\title{
Reflections on the teaching of systems thinking to psychiatric registrars
}

\author{
Anne McFadyen and Jane Roberts
}

\begin{abstract}
Registrars in psychiatiy do not routinely hove the opportunity to leam about systems theory and its application to psychiatric practice. The authors describe their experience of organising and teaching a course on the application of systems thinking to psychiatry and family therapy. The trainees and their tutor welcomed the broad and interactive approach to teaching which was thought to be very relevant to training in all psychiatric sub-speciallitios.
\end{abstract}

We are sharing our experience of teaching a course entitled 'Applications of Systemic Thinking of Psychiatry and Family Therapy' to psychiatric trainees. While the primary motivation was to fulfil the teaching practice requirements of the MSc degree in family therapy that we were both undertaking, we became enthused by a style of teaching that incorporated systemic ideas into the process itself. This article attempts to capture some of the interest and enthusiasm shared by both of us, many of the trainees and trainers on the psychiatric training scheme.

\section{Our context}

As trainees on the MSc course run jointly by the Tavistock Clinic and Brunel University, we were required to organise and teach an introductory course on family therapy or related subject to take place over at least 12 sessions. Who and where we taught was a matter for us to decide and negotiate.

As senior registrars in child psychiatry at the Tavistock Clinic, we had both worked at the Royal Free Hospital and therefore had some familiarity with the hospital. We approached the co-ordinating tutor there to see if such a course might be welcomed. Our personal context, that we were both heavily pregnant at the time, was of considerable relevance to our wish to teach locally. Our overtures were eagerly greeted and preparations for a course, Applications of Systemic Thinking to Psychiatry and Family Therapy' begun. We were keen not to restrict the course to family therapy alone, preferring a more challenging project to consider the application of systems thinking on a broader level. What is systems thinking? Is it significantly different from other modes of thinking? What is its relevance to psychiatrists both in their direct clinical work with patients and in their relationships with other professionals? Our own training as psychiatric registrars had dealt with such issues scantily, if at all.

\section{Registrar's context}

There was in existence at the time a wellestablished academic programme for the registrars on the psychiatric rotation at the Royal Free Hospital; our course would therefore have to be accommodated within a defined structure. More dauntingly, it would be competing for time and interest with a course explicitly designed to help registrars get through Part II of the MRCPsych examination. Finally, we had to contend with the demands of the clinical work on registrars' time.

\section{Setting up}

We wished to encourage to enrol on the course only those trainees who were interested and willing to commit themselves to attend regularly and to participate actively. To this end, as part of our marketing strategy we circulated an initial 'flyer' advertising the course six months before it was to start. Three months later, a more detailed circular and application forms were made avallable to the whole group of psychiatric registrars on the North London rotation. Places were limited to 15 and applicants were asked to write a brief statement about why they wanted to come on the course.

Sixteen applications were received, minimally higher than the number of places we had specified. In view of the efforts made by all those who applied, we felt that it would have been invidious to reject just one individual and accordingly, accepted all 16. 
EDUCATION

Table 1. Course outline

\begin{tabular}{|c|c|c|}
\hline Sescion & Tite & Content \\
\hline $\begin{array}{l}1 \\
2 \\
3\end{array}$ & $\begin{array}{l}\text { Introductory half day workshop } \\
\text { More about systems thinking } \\
\text { Family systems and life cycles }\end{array}$ & $\begin{array}{l}\text { Systems thinking: What is it? Why is it useful? Basic theory } \\
\text { and key concepts e.g. feedback, context interaction. } \\
\text { Application to medicine in general, psychiatry in } \\
\text { particular. Role of the trainee in the institution, } \\
\text { communication within and outwith the organisation. } \\
\text { Institutional processes. }\end{array}$ \\
\hline $\begin{array}{l}4 \\
5 \\
6 \\
7\end{array}$ & $\begin{array}{l}\text { Thinking about families } \\
\text { Different theoretical } \\
\text { perspectives and } \\
\text { skills development }\end{array}$ & $\begin{array}{l}\text { Family therapy: What is it? Why use it? Similarities and } \\
\text { differences - schools of family therapy } \\
\text { What skills are needed? Which situations? Role of the } \\
\text { therapist. Techniques in therapy and supervision. }\end{array}$ \\
\hline 8 & $\begin{array}{l}\text { Attachment theory and family } \\
\text { therapy }\end{array}$ & $\begin{array}{l}\text { Psychiatry: training, research and service. Specific toplcs, } \\
\text { e.g. anorexia nervosa, schizophrenia and EE, depression. }\end{array}$ \\
\hline $\left.\begin{array}{c}9 \\
10 \\
11\end{array}\right\}$ & $\begin{array}{l}\text { Mental illness from a systems } \\
\text { perspectlve } \\
\text { Psychosomatic illness and } \\
\text { liaison work }\end{array}$ & $\begin{array}{l}\text { Useful theories or belief systems, e.g. attachment theory } \\
\text { and its application. }\end{array}$ \\
\hline $\begin{array}{l}12 \\
13\end{array}$ & $\begin{array}{l}\text { Institutions and consultations } \\
\text { Finale: half day workshop }\end{array}$ & \\
\hline
\end{tabular}

\section{Structure of the course}

We began and ended with a half-day workshop but otherwise met weekly for two and a quarter hours from February to June. Two breaks had to be fitted into the programme and we were keen for these to be used positively. Coffee - an essential component - was provided by us in the quarter of an hour break in the middle of each session. The importance of both punctuality and, when necessary, sending apologles for absence was stressed in an attempt to heighten a sense of commitment and ensure clear boundaries for the course.

Our aims were to consider the application of Systems Theory to mental health work, and to introduce participants to relevant family therapy theory and techniques. We chose to do this by focusing on three main topics: systems thinking. family therapy, and psychiatry. Our intention was to relate the trainees' context, psychiatry, to the teaching at every stage, as well as to consider specific ideas of relevance to psychiatrists. We set out to ask some questions, give information and encourage trainees to begin to explore the relevance of systemic thinking to their own work.

We believed that it was important not only to teach about systems thinking but also to make the experience a systemic one. We wanted the trainees both to learn about systems and to be systemic. To that end, we tried to take account of the process of the course as well as the content. For example, we encouraged feedback and drew attention to context and circularity at every opportunity. We began by marrying their agenda to our own, and were heartened to find that their needs were similar to our own perceptions of what it would be helpful for them to know. The formal course plan was drawn up following our first meeting and the content and shape reflected this initial discussion. (This course outline is detailed in Table 1).

A variety of teaching styles was used to enact ways of working with families and other groups, to maintain the trainees' interest and curiosity and also to teach about teaching. Again, a systemic approach was adhered to. A reading list for the course was supplied and in some sessions trainees were asked to present and discuss particular papers. We included 'classics' such as extracts from Bateson's Mind and Nature (1979) and accounts of particular approaches (structural, strategic and Milan therapies). Mindful of our context, we prescribed papers directly relevant to psychiatry, for example Rosenhan's 'On being sane in insane places' (1973) and the British Journal of Psychiatry supplement 'Schizophrenia as a systems disorder' (Brenner \& Boker, 1989). Also included, for amusement and to persuade our trainees that 'systems are everywhere' was 'Diet, diabetes and male chauvinism' (Probert et al, 1990).

In order to address a broader context, newspaper articles were culled. For example, the difficulties of resolving problems in Northern Ireland were considered in this light; 'Death seen as way of life in stalemate' (The Guardian, 4 January, 1991) exemplified the no change position. Other exercises focused on boundary, punctuation, context and reframing, aided and 
abetted by the Sun, Daily Mirror, Daily Telegraph and The Guardian. The Butcher family's therapy session from Eastenders helped us to talk about how not to do family therapy.

Brainstorming sessions, video, sculpting, and role-play were used and despite the strong reservations of one of us about the latter, role-play sessions were entered into wholeheartedly by the trainees. Trainees were also asked to chair some sessions and again committed themselves readily to this task.

A specific strategy adopted attempted to capitalise on the fact that there were two of us teaching. We openly acknowledged our similarities and differences and at times more formally discussed our own beliefs and ideologies, using the 'split' between us to fuel debate. One of us was more sceptical than the other about the distinctiveness of the systemic approach. She believed that 'systemic ideas' were fundamental to the theory of medicine, if not always applied in practice. Towards the end of the course, we asked the trainees to interview us together, using the skills they had learned on the course. Our aim was to reflect a systemic philosophy by attending to group processes, and by specifically drawing attention to our own interaction.

\section{Our views}

We thought that the course went well. Most trainees participated enthusiastically.

After the first session we felt good. It had been lively and stimulating for both trainers and trainees. In contrast the second session was like a damp squib. We were dismayed, but later heartened to read that:

"Not infrequently, the first session ends with relief and thrill. For the teacher, the course is up and running. The teaching in the first session has the immediate effect of creating connections in the teaching-learning system and the teacher's capacity to respond to feedback is tested.

In contrast to the first, the second session, mirroring the therapeutic process, often feels like a hard slog." Campbell, Draper \& Huffington (1988)

In the third session, we shared this with the group and got back on track. By the time of the first break we felt that there was a cohesiveness about the group and a coherence about the course that would sustain it.

During the second phase, with family therapy as the main focus, we invited the trainees to bring cameos of their own cases. These were used as the foundation for skills development and experiential learning through role-play. The similarities and differences between different schools of family therapy were explored, with socio-political and professional contexts in mind.

It seemed important to us that the trainees' own strengths should be emphasised in the third phase. The topic, psychiatry, belonged to them, and together we explored different theories important to psychiatry as a whole. For example, in session 11, trainees were divided into small groups, each of which was asked to construct their own theory to explain psychosomatic illness. This session was videotaped for our own training purposes, but despite being determined to be at our sharpest, we both found ourselves caught up in one group's presentation. A diagram showing a balance with weights hanging on either side seemed to one of us to be a row of dummies (pacifiers). The other, noting her companion's perplexity, was able to say aloud to her, "You thought they were dummies didn't you?" She confessed to the group that her personal context, motherhood, seemed to have influenced her perception of what was on offer. The importance of context, and the validity of the constructivist position, was emphasised.

Interestingly the second last session, as well as the second, seemed to miss the mark. The topic was 'institutions and consultation'. Our impression was that our familiarity as child psychiatrists with ideas about consultation to institutions had led us to somehow forget that there was a stage in our careers when we had been unfamiliar with this way of working. The trainees were not as ready to grasp the subject as we had expected. Given a registrar's position within a complex network of agencies, this seemed particularly ironical.

Our own analysis, described in part above, was that the course had been well organised and well run. With two exceptions the sessions had been lively and trainees had participated well. The difficulties in managing such a large group on an interactive and experiental course were considerable but not insurmountable. We learnt about the importance of our own context. Each trainee's context could perhaps have been attended to in more detail.

\section{Feedback}

As well as asking for feedback throughout, we also gave the trainees a form to complete about their experience of the course at the end of the last session. Out of 16,13 were returned. They were asked to rate the course for relevance to training, enjoyment and content; and also asked to rate the value of different methods of teaching, namely reading, discussion of papers, didactic teaching, use of video material, role play, small group exercises and large group discussion. Ratings were on a scale from 1 (least or poor) to 5 (most or good). 
Relevance to training was rated 4 by five respondents or 5 by eight. Enjoyment and content were similarly highly rated with one exception who rated content as 2 . The most popular methods of teaching were the use of videos and role plays: each scored 5 on 11 occasions and 4 on two. Reading and discussion of papers were favoured next with most trainees giving these methods a 4 . The other methods were not scored unfavourably with large and small group methods also scoring mostly $4 \mathrm{~s}$ and $5 \mathrm{~s}$. Didactic teaching was scored 3 by half with the others rating it at 4 or 5 . One trainee said that we hadn't done any didactic teaching at all.

Our questionnaire also included some semistructured questions and provided space for additional comment. These comments reflected the trainees' enthusiasm for role-play which was both described as most enjoyable and most informative. The sessions on psychosomatic families, attachment and different family therapy styles and techniques were also considered to be very useful. Most thought that the course could be improved but comments were divided about the way to do this. Many emphasised the value of role-play and viewing video and requested more. Two advocated more risk-taking by trainees while, at the other end of the spectrum, two had felt threatened at times by their colleagues and felt that we should have paid more attention to group dynamics. This last comment was of concern to us. While aware that about a third of the group was vocal and obviously enthusiastic, we had not appreciated that this was intimidating at times for some of the others. We were pleased that this had been pointed out, but sorry that we had not this feedback earlier.

The academic tutor later spoke enthusiastically about our course; more trainees than usual had enrolled and continued to attend despite it being longer than most. It provided the only opportunity for thinking about work with families on the academic programme. Family therapy was seen very much as the remit of child psychiatrists even though it was acknowledged that it was very relevant to general psychiatry. He valued particularly the focus of our course on wider issues relevant to psychiatric trainees. He supported the notion that trainees should be exposed to a broader and more creative curriculum rather than confined to the demands of the MRCPsych examination.

\section{Conclusion}

This was an experiment in training. Registrars are not often given the opportunity to learn about, the appreciate the relevance of, a systemic approach in psychiatry. Our course successfully addressed both theory and practice, and was well received by the trainees and their academic tutor.

\section{Acknowledgements}

We thank Judy Hildebrand and Michael King for their support, and the trainees for their contribution and enthusiasm, and Beth Gow.

\section{References}

BAteson, G. (1979) Mind and Nature: a necessary unity. London: Wildwood House.

BRENNER, H.D. \& BOKER. W. (1989) Schizophrenia as a systems disorder. British Journal of Psychiatry. 156, Supplement 5.

CAMPBEll, D., DRAPER, R. \& Huffington, C. (1988) Teaching Systemic Thinking. P 34. London: D.C. Associates.

Probert, C.S. et al (1990) Diet, diabetes, and male chauvinism. British Medical Journal, 301, 1430-1431.

RosenhaN, D.L. (1973) On being sane in insane places. Sclence, 179, 250-258.

The Guardian, 4 January 1991.

*Anne McFadyen, Senior Lecturer in Child and Adolescent Psychiatry, University of Dundee, Dudhope House, 15 Dudhope Terrace, Dundee DD3 6HH; and Jane Roberts, Consultant Child and Adolescent Psychiatrist, Camden and Islington Community NHS Trust and Whittington Hospital, London

*Correspondence

The course reading list is available on request. 